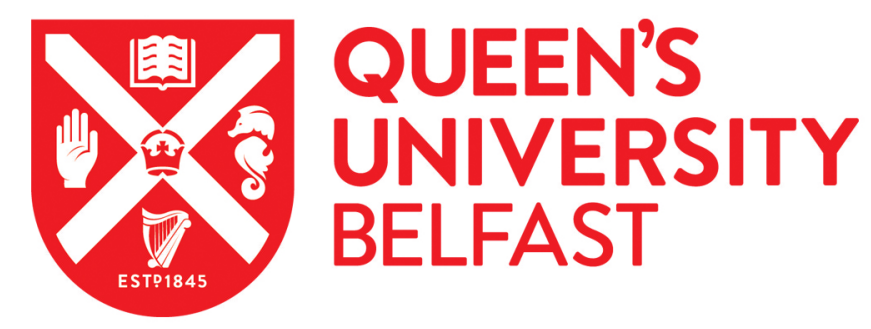

\title{
Soil attribute regulates assimilation of roxarsone metabolites by rice (Oryza sativa L.)
}

Yao, L., Carey, M. P., Zhong, J., Bai, C., Zhou, C., \& Meharg, A. A. (2019). Soil attribute regulates assimilation of roxarsone metabolites by rice (Oryza sativa L.). Ecotoxicology and Environmental Safety, 184, [109660]. https://doi.org/10.1016/j.ecoenv.2019.109660

Published in:

Ecotoxicology and Environmental Safety

Document Version:

Peer reviewed version

Queen's University Belfast - Research Portal:

Link to publication record in Queen's University Belfast Research Portal

Publisher rights

(c) 2019 Elsevier Inc. All rights reserved.

This manuscript version is made available under the CC-BY-NC-ND 4.0 license http://creativecommons.org/licenses/by-nc-nd/4.0/,which permits distribution and reproduction for non-commercial purposes, provided the author and source are cited.

\section{General rights}

Copyright for the publications made accessible via the Queen's University Belfast Research Portal is retained by the author(s) and / or other copyright owners and it is a condition of accessing these publications that users recognise and abide by the legal requirements associated with these rights.

Take down policy

The Research Portal is Queen's institutional repository that provides access to Queen's research output. Every effort has been made to ensure that content in the Research Portal does not infringe any person's rights, or applicable UK laws. If you discover content in the Research Portal that you believe breaches copyright or violates any law, please contact openaccess@qub.ac.uk. 
1 Soil attribute regulates assimilation of roxarsone metabolites by rice (Oryza

2 sativa $\mathbf{L}$.)

3 Lixian Yao ${ }^{\mathrm{a}, \mathrm{b}}$, Manus P. Carey ${ }^{\mathrm{a}}$, Jiawen Zhong ${ }^{\mathrm{b}}$, Cuihua Bai ${ }^{\mathrm{b}}$, Changmin Zhou ${ }^{\mathrm{b}}$,

4 Andrew A. Meharg a, *

5

6 a Institute of Global Food Security, Queen's University Belfast, Belfast BT9 7BL, UK

$7 \quad$ b College of Natural Resources and Environment, South China Agricultural

8 University, Guangzhou 510642, China

9

10 Corresponding author: Andrew A. Meharg, Ph. D \& Prof.

11 Address:

12 Institute of Global Food Security, Queen's University Belfast, Belfast BT9 7BL

13 UK

14 Tel: $+44(0) 2890975413$

15 E-mail address: aa.meharg@qub.ac.uk 
17 Roxarsone (ROX), an organoarsenic feed additive, and its metabolites, can be present

18 in animal manure used to fertilize rice. Rice is prone to absorb arsenic, and is subject

19 to straighthead disorder, which reduces rice yield and is linked with organic arsenic

20 compounds. This study aims to elucidate how soil property affect arsenic

21 accumulation in rice plants fertilized with chicken manure containing ROX metabolites. Manures of chickens fed without or with ROX, designated as control manure and ROX treated manure (ROXCM), respectively, were applied in eight

24 paddy soils of different origins, to investigate the assimilation of arsenic species in rice plants. The results show that inorganic arsenic (arsenate and arsenite), monomethylarsonic acid and dimethylarsinic acid (DMA) were detected in all brown rice and husk, trace tetramethylarsonium and trimethylarsine oxide were occasionally

28 found in these both parts, whereas all these arsenic species were determined in straw,

29 irrespective of manure type. ROXCM application specifically and significantly

30 increased brown rice DMA $(\mathrm{P}=0.002)$, which remarkably enhanced the risk of

31 straighthead disease in rice. Although soil total As impacted grain biomass, soil free-

32 iron oxides and $\mathrm{pH}$ dominated arsenic accumulation by rice plants. The significantly

33 increased grain DMA suggests manure bearing ROX metabolites is not suitable to be

34 used in soils with abundant free-iron oxides and/or high $\mathrm{pH}$, if straighthead disorder is 35 to be avoided in rice. 
37 Keywords: Roxarsone; Animal manure; Rice; Arsenic species; Paddy soil; Soil 38 property 


\section{Introduction}

Roxarsone (4-hydroxy-3-nitro-phenylarsonic acid, ROX), an organoarsenic feed

41 additive in animal production, occurs as itself and its metabolites in animal manure, which is commonly land applied as fertilizer in crop production. ROX metabolites in the manure include inorganic arsenic [iAs, the sum of $\mathrm{As}(\mathrm{V})$ and $\mathrm{As}(\mathrm{III})]$, monomethylarsonic acid (MMA), dimethylarsinic acid (DMA), 3-amino-4hydroxyphenylarsonic acid (3-AHPA), 3-acetamido-4-hydroxy-phenylarsonic acid (3AAHPA) and so on, with iAs dominating (Fisher et al., 2015; Yang et al., 2016; Yao et al., 2016).

Arsenic phytoavailability is closely related to soil properties (Datta et al., 2006; Fu et al., 2011). Soil exchangeable calcium promotes iAs uptake in garland chrysanthemum fertilized from chicken manure contaminated with ROX metabolites

51 (Yao et al., 2017). As(III) and DMA are the primary arsenic species in vegetables grown in aerobic medias amended with chicken manure containing ROX metabolites (Huang et al., 2014; Yao et al., 2009).

Rice, the staple food for about half of the world population (Zhu et al., 2008), is prone to absorb arsenic than other staple food due to its soil anaerobic growth environment, and to highly efficient arsenic transport mechanisms ( $\mathrm{Su}$ et al., 2010; Williams et al., 2007). Rice consumption is the largest contributor of total iAs intake in Southeast Asia and China (Li et al., 2011; Meharg et al., 2009; Mondal and Polya, 2008), consequently, arsenic accumulation in rice is of global concern. It is reported 
60 that rice grain arsenic is significantly enhanced by addition of ROX to paddy soils

61 (Liu et al., 2009; Wang et al., 2006). However, it is ROX metabolites, rather than

62 ROX itself, that are inevitably introduced into soils as animal manure is land applied

63 as fertilizer. Rice is commonly grown in flooded soils, where the bioavailability of

64 ROX metabolites might be different from that in the aerobic media as irrigation

65 management markedly affects the uptake of arsenic species in rice plant (Carrijo et al., 66 2019).

67 The transfer of ROX from chicken diet to rice plant has been documented (Yao et al., 2016). In the present study, we further compare the uptake of arsenic species by rice plants in eight typical paddy soils from China, where two chicken manures, without or with ROX metabolites, were applied, with the aim to identify how soil

71 attributes govern the phytoavailability of ROX metabolites to rice plants, focusing on 72 the edible grain.

\section{2. Material and methods}

\subsection{Chicken manure}

Manures were produced from a chicken farm located in Huizhou city, Guangdong province, South China. Two groups of chickens (1320 chickens in each group) of the same breed and age ( $45 \mathrm{~d}$ ), were simultaneously fed with ROX contrasting diets. One diet was a typical maize - soybean meal feed without ROX, and the other one was the

79 same formula added with ROX at the recommended dose of $50 \mathrm{mg} \mathrm{kg}^{-1}$. The ROX 
80 (98.0\%) was purchased from Zhejiang Rongyao Biotech Co., Ltd, China. Two

81 manures excreted by these two groups of chickens were separately collected,

82 composted for $20 \mathrm{~d}$ and then air dried, ground and $2 \mathrm{~mm}$-sieved for use, respectively.

83 The control manure without ROX was designated as CM and the ROX-treated manure

84 as ROXCM. Sieved manure samples were collected for total arsenic and arsenic

85 speciation. Some selected attributes of these both manures are listed in Table 1.

$86 \quad$ Table 1

87 Selected properties of two chicken manures without $(\mathrm{CM})$ or bearing roxarsone

88 metabolites (ROMCM).

\begin{tabular}{lll}
\hline Item & $\mathrm{CM}$ & ROXCM \\
\hline $\mathrm{pH}$ & 7.04 & 7.07 \\
$\mathrm{OM}\left(\mathrm{g} \mathrm{kg}^{-1}\right)$ & $502.9 \pm 6.6$ & $510.6 \pm 17.6$ \\
Total N $\left(\mathrm{g} \mathrm{kg}^{-1}\right)$ & $73.2 \pm 1.8$ & $72.4 \pm 1.0$ \\
Total arsenic $\left(\mathrm{mg} \mathrm{kg}^{-1}\right)$ & $1.4 \pm 0.1$ & $33.2 \pm 0.9$ \\
Roxarsone $\left(\mathrm{mg} \mathrm{kg}^{-1}\right)$ & $\mathrm{nd}$ & $0.36 \pm 0.06$ \\
3-AHPA $\left(\mathrm{mg} \mathrm{kg}^{-1}\right)$ & nd & $4.82 \pm 0.28$ \\
3-AAHPA $\left(\mathrm{mg} \mathrm{kg}^{-1}\right)$ & nd & $0.79 \pm 0.02$ \\
MMA (mg kg-1) & nd & $0.11 \pm 0.02$ \\
DMA (mg kg & & $0.76 \pm 0.05$ \\
& $0.40 \pm 0.0$ & $25.9 \pm 0.4$ \\
\hline
\end{tabular}


91 China. All the soils were collected at 0-25 cm depth, air-dried and then $2 \mathrm{~mm}$-sieved

92 and well mixed. The basic location information of soils is present in Table S1

93 (supporting material). planted in South China, was used. The rice seed was supplied by the Rice Research Institute, Guangdong Academy of Agricultural Sciences. The sterilized seeds were sown into a plastic plate filled with growth substrate (coconut husk:pearlite, $3: 1$ ), and irrigated with Hoaglands nutrient solution. After being grown for $20 \mathrm{~d}$, the seedlings

100 were transplanted for culture experiment. conducted in a randomized pot experiment in the green house. In each PVC pot, $100 \mathrm{~g}$

104 (DW) of each manure and $4 \mathrm{~kg}$ of each soil were mixed thoroughly. No other

105 fertilizers were added. The soils were flooded for 1 week by adding tap water, and

106 then two 20-day-old seedlings were transplanted into each pot. Rice plants were

107 flooded with 2-3 cm deep water till grain filling, followed by intermittent irrigation

108 till one week before harvest when the soils were drained. 
Rice grains and straws were harvested at $106 \mathrm{~d}$ after transplanting. The air-dried

111 grain weight was recorded before being dehusked to produce brown rice and husk,

112 and the fresh weight of rice straw was also recorded. Then, all the brown rice, husk

113 and straw samples were lyophilized (Alpha 1-4/LD-plus, Christ) and pulverized by a

114 ball mill (Retsch PM 100) to fine powder for total arsenic and arsenic speciation

115 analysis.

116 Total arsenic in plant, manure and soil samples was extracted by 1:1 mixture of

117 concentrated $\mathrm{HNO}_{3}$ and $\mathrm{H}_{2} \mathrm{O}_{2}$, and then microwave-digested using appropriate

118 digestion programs, respectively. The internal standard rhodium (Fluka Analytical

119 ICP-MS standard) was used at the concentration of $10 \mu \mathrm{g} \mathrm{kg}^{-1}$ to assure the detection

120 quality. The final digestate was detected using ICP-MS (Thermo Scientific iCap Q)

121 for total arsenic. Arsenic species in plant tissues were extracted with $1 \%$ concentrated

$122 \mathrm{HNO}_{3}$ and microwave-digested. $1 \mathrm{~mL}$ of the digested plant solution was transferred to

123 the vial, and $10 \mu \mathrm{L}$ of $30 \% \mathrm{H}_{2} \mathrm{O}_{2}$ was added into the vial to oxidize $\mathrm{As}(\mathrm{III})$ to $\mathrm{As}(\mathrm{V})$,

124 and the final solution was subjected to IC-ICP-MS for arsenic speciation using the

125 same methods and instruments as described by Signes-Pastor et al. (2017). Arsenic

126 species in manure and soils were extracted with mixture of $65 \% 50 \mathrm{mM}\left(\mathrm{NH}_{4}\right)_{2} \mathrm{HPO}_{4}$

$127+35 \%$ methanol $(\mathrm{pH}=6.5)$ for $10 \mathrm{~h}$ at $45^{\circ} \mathrm{C}$, and the extracts were purified by solid-

128 phase cartridges (500 mg $6 \mathrm{~mL} \mathrm{~min}^{-1}$, Nu Analytical Technology, USA), followed by

$1290.22 \mu \mathrm{m}$ films. The filtrates were collected for arsenic speciation as well. The 
$131 \mathrm{As}(\mathrm{III}), 94.0 \pm 4.0 \%$ for MMA and $102.2 \pm 2.6 \%$ for DMA in soil, and those were $90.3 \pm 5.3 \%$ for ROX, $87.3 \pm 8.9 \%$ for 3 -AHPA, $97.2 \pm 4.5 \%$ for 3 -AAHPA, $100.1 \pm 6.0 \%$

133 for $\mathrm{As}(\mathrm{V}), 115.0 \pm 2.3 \%$ for $\mathrm{As}(\mathrm{III}), 79.4 \pm 2.5 \%$ for MMA and $114.4 \pm 3.2 \%$ for DMA in 134 manure.

135 Soil texture was measured by Bouyocos hydrometer, and soil $\mathrm{pH}$ was determined 136 in the suspension of 1:2.5 (soil:water, w/w). Soil organic matter (OM) was quantified 137 using $\mathrm{K}_{2} \mathrm{Cr}_{2} \mathrm{O}_{7}$ oxidation in oil bath method. Soil cation exchangeable capacity (CEC) 138 was evaluated with titrimetric analysis using $1 \mathrm{M} \mathrm{CH}_{3} \mathrm{COONH}_{4}$ saturation. The soil's 139 free-iron oxides were extracted by mixture of $0.3 \mathrm{M} \mathrm{Na}_{3} \mathrm{C}_{6} \mathrm{H}_{5} \mathrm{O}_{7}+1 \mathrm{M} \mathrm{NaHCO}_{3}+0.5$

$140 \mathrm{~g} \mathrm{Na}_{2} \mathrm{~S}_{2} \mathrm{O}_{4}$ and then measured by phenanthroline colorimetry. Soil exchangeable $\mathrm{Ca}$

141 and $\mathrm{Mg}$ were extracted with $1 \mathrm{M} \mathrm{CH}_{3} \mathrm{COONH}_{4}$ and then detected by atomic

142 adsorption spectrometry, respectively. Soil Olsen-P was extracted using 0.5 M

$143 \mathrm{NaHCO}_{3}$ and determined by Mo-Sb colorimetric method. Analysis methods of the

144 above soil properties are depicted by $\mathrm{Lu}$ (2000). Soil total Fe and Mn were measured 145 with the same method as total arsenic using ICP-MS.

\subsection{Standards and reagents}

148 containing certified levels of total arsenic and several arsenic species were used to

149 guarantee the analysis quality of total arsenic and arsenic speciation during the 
experiment. The recoveries of total arsenic, iAs, MMA and DMA were $77.4 \pm 3.0 \%$, $99.3 \pm 4.6 \%, 97.3 \pm 3.1 \%$ and $102.0 \pm 3.2 \%$, respectively. Reference materials or pure compounds of ROX (Sigma-Merck, Vertanal $\left.{ }^{\mathrm{TM}}\right)$, 3-AHPA (Pfaltz \& Bauer), 3-

157 The detection limits of all arsenic species were $\leq 2.0 \mu \mathrm{g} \mathrm{kg}^{-1}$. Multi-Element 2 (Spex

158 Clms-2 Multi-Element Solution 2, matrix: 5\% $\mathrm{HNO}_{3}$ ) and Multi-Element 4 (Spex

159 Clms-4 Multi-Element Solution 4, matrix: water/Tr-HF) were used to make up all

160 standard solutions in the ranges of $0,0.1,0.3,1,3,10,30$ and $100 \mu \mathrm{g} \mathrm{kg}^{-1}$ for total

161 arsenic analysis. Ultrapure water was prepared with Millipore Milli-Q Academic.

\subsection{Data statistics}

163

All the data were the means of four replicates, and expressed as mean \pm standard

164 deviation. The significance of the effect of manure type and soil type was tested by

165 two-way analysis of variance (ANOVA), followed by comparisons of means using

166 Duncan's. Stepwise linear regression analysis were performed using SAS/STAT (9.2)

167 software. The symbols ${ }^{*},{ }^{* *}$ and ${ }^{* * *}$ show statistical significance at $0.05,0.01$ and

1680.001 level, respectively. All variables left in the stepwise regression models are

169 significant at 0.05 level.

\section{Results and discussion}


172

173

174

175

176

177

$178{ }^{1}$, respectively. These soils contained $8.4 \sim 54.7 \mathrm{mg} \mathrm{kg}^{-1}$ of total Fe, $1.4 \sim 30.3 \mathrm{mg} \mathrm{kg}^{-1}$

179 of free-iron oxides and 59 930 $\mathrm{mg} \mathrm{kg}^{-1}$ of total Mn, respectively. Soil total arsenic

180 was in the range of $1.8 \sim 25.0 \mathrm{mg} \mathrm{kg}^{-1}$. As(V) was the dominating arsenic species

181 detected in all soils, with the concentrations of $0.57 \pm 0.38 \sim 9.69 \pm 0.19 \mathrm{mg} \mathrm{kg}^{-1}$. As(III)

182 was analyzed at low levels in six soils, with the exception of Soil FJ and Soil SC.

183 DMA was only found in Soil PY, and MMA was observed in Soil GZ and Soil PY.

184 The above indicates that these soils considerably differed in physiochemical

185 properties.

186

Table 3

187 Arsenic species in eight paddy soils.

\begin{tabular}{lllll}
\hline Soil & $\mathrm{As}(\mathrm{V})\left(\mathrm{mg} \mathrm{kg}^{-1}\right)$ & $\mathrm{As}(\mathrm{III})\left(\mathrm{mg} \mathrm{kg}^{-1}\right)$ & $\mathrm{DMA}\left(\mathrm{mg} \mathrm{kg}^{-1}\right)$ & $\mathrm{MMA}\left(\mathrm{mg} \mathrm{kg}^{-1}\right)$ \\
\hline Soil GZ & $9.47 \pm 0.27$ & $0.32 \pm 0.06$ & $<\mathrm{LOD}$ & $0.09 \pm 0.02$ \\
& & & & \\
Soil PY & $9.69 \pm 0.19$ & $0.38 \pm 0.01$ & $0.05 \pm 0.0$ & $0.07 \pm 0.02$
\end{tabular}




\begin{tabular}{lllll} 
Soil GX & $1.44 \pm 0.08$ & $0.07 \pm 0.01$ & $<$ LOD & $<$ LOD \\
Soil FJ & $0.57 \pm 0.38$ & $<$ LOD & $<$ LOD & $<$ LOD \\
Soil HB & $4.89 \pm 0.09$ & $0.06 \pm 0.03$ & $<$ LOD & $<$ LOD \\
Soil SC & $3.16 \pm 0.18$ & $<$ LOD & $<$ LOD & $<$ LOD \\
Soil SX & $6.65 \pm 0.28$ & $0.04 \pm 0.02$ & $<$ LOD & $<$ LOD \\
Soil AH & $4.33 \pm 0.46$ & $0.40 \pm 0.02$ & $<$ LOD & $<$ LOD \\
\hline
\end{tabular}

188 
Table 2

190 Selected properties of eight paddy soils.

\begin{tabular}{|c|c|c|c|c|c|c|c|c|c|c|c|c|c|}
\hline \multirow{5}{*}{ Soil } & \multirow{5}{*}{$\begin{array}{l}\text { Clay } \\
\left(\mathrm{g} \mathrm{kg}^{-1}\right)\end{array}$} & \multirow{5}{*}{$\begin{array}{l}\text { Silt } \\
\left(\mathrm{g} \mathrm{kg}^{-1}\right)\end{array}$} & \multirow{5}{*}{$\begin{array}{l}\text { Sand } \\
\left(\mathrm{g} \mathrm{kg}^{-1}\right)\end{array}$} & \multirow{5}{*}{$\mathrm{pH}$} & Organic & CEC & \multirow{5}{*}{$\begin{array}{l}\text { Olsen-P } \\
\left(\mathrm{mg} \mathrm{kg}^{-1}\right)\end{array}$} & Exchangeab & Exchangeab & Total Fe & Free-iron & \multirow{5}{*}{$\begin{array}{l}\text { Total Mn } \\
\left(\mathrm{mg} \mathrm{kg}^{-1}\right)\end{array}$} & \multirow{4}{*}{$\begin{array}{l}\text { Total } \\
\text { arsenic }\end{array}$} \\
\hline & & & & & & & & \multirow{3}{*}{ le Ca (mg } & \multirow{3}{*}{ le Mg (mg } & \multirow{3}{*}{ (mg kg- } & & & \\
\hline & & & & & matter (g & $(\mathrm{cmol}(+)$ & & & & & oxides (g & & \\
\hline & & & & & & & & & & & & & \\
\hline & & & & & $\left.\mathrm{kg}^{-1}\right)$ & $\left.\mathrm{kg}^{-1}\right)$ & & $\left.\mathrm{kg}^{-1}\right)$ & $\left.\mathrm{kg}^{-1}\right)$ & 1) & $\left.\mathrm{kg}^{-1}\right)$ & & $\left(m g \mathrm{~kg}^{-1}\right)$ \\
\hline Soil GZ & 144.0 & 352.4 & 503.6 & 6.15 & 26.2 & 11.35 & 49.0 & 1259 & 19 & 29.3 & 15.4 & 281 & 15.2 \\
\hline Soil PY & 417.6 & 538.9 & 43.5 & 5.17 & 23.7 & 36.30 & 156.9 & 737 & 206 & 54.7 & 30.3 & 631 & 25.0 \\
\hline Soil GX & 106.0 & 247.3 & 646.7 & 6.31 & 18.6 & 6.80 & 49.1 & 939 & 18 & 12.0 & 8.0 & 59 & 3.3 \\
\hline Soil FJ & 103.2 & 353.8 & 543 & 5.54 & 36.4 & 12.55 & 45.4 & 645 & 43 & 8.4 & 1.4 & 388 & 1.8 \\
\hline Soil HB & 345.6 & 543.2 & 111.2 & 8.14 & 31.6 & 31.20 & 15.5 & 3844 & 320 & 38.4 & 13.9 & 706 & 9.5 \\
\hline Soil SC & 191.2 & 491.2 & 317.6 & 7.44 & 20.9 & 19.10 & 7.9 & 3601 & 111 & 26.0 & 6.4 & 697 & 5.9 \\
\hline Soil SX & 257.2 & 664.4 & 78.4 & 7.34 & 55.3 & 18.55 & 70.8 & 5092 & 294 & 38.0 & 10.8 & 930 & 10.3 \\
\hline
\end{tabular}


$\begin{array}{llllll}\text { Soil AH } & 238.0 & 744.7 & 17.3 & 5.62 & 20.0\end{array}$

191
19.65

31.4

2101

179

23.3

12.8

239

8.1 
194 produced in soils amended with two manures $(\mathrm{P}=0.901)$, irrespective of ROX metabolites in the manure or not (Fig. 1). The plant biomass in the present work further confirms our previous observation that ROX addition at allowable dose in chicken diet did not suppress rice growth (Yao et al., 2016), which was ascribed to the nourishment of the manure to rice plant and low concentrations of ROX metabolites in these ROXCM-amended soils . The growth response of rice plant to ROX metabolites in the manure differed from the previous studies (Liu et al., 2009; Wang et al., 2006), where rice biomass was significantly decreased by external ROX addition directly in soils at high levels, e.g., $\geq 10 \mathrm{mg} \mathrm{As} \mathrm{kg}^{-1}$ or $\geq 25 \mathrm{mg} \mathrm{ROX} \mathrm{kg}$.

203 However, both grain and straw biomass was significantly influenced by soil type $204(\mathrm{P}=0.008$ and 0.004$)$, implying that soil properties dominated the growth of rice plant 205 fertilized with two manures in the present work. on soil total As since the variance of soil total As explained $90.5 \%(\mathrm{P}<0.001)$ and $73.9 \%(\mathrm{P}=0.006)$ of the variability of grain biomass in $\mathrm{CM}$ - and ROXCM-amended

209 soils, respectively. Soil clay had the main effect on straw biomass in CM-amended

210 soil, the difference of which contributed to $70.7 \%(\mathrm{P}=0.009)$ of the variance of straw 211 biomass. However, no dominating soil factor was observed for straw biomass in 
212 ROXCM-amended soil because no variable met the 0.050 significance level for entry

213 into the model between straw biomass and soil attribute. The above indicates that rice

214 grain was more sensitive to soil arsenic than rice straw.

215

216
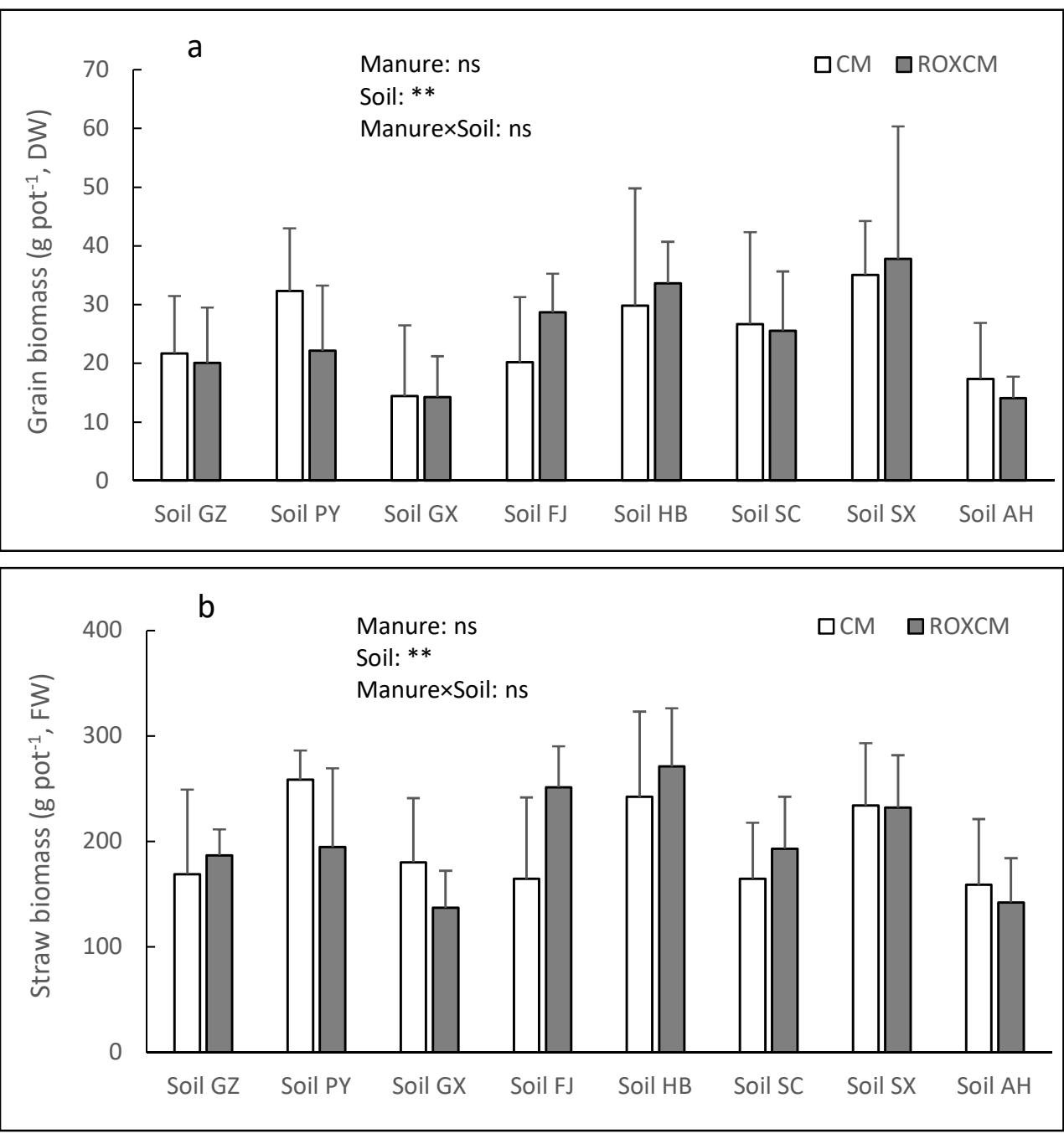

218 Fig. 1. Biomass of rice plants (a: grain; b: straw) grown in eight soils fertilized with

219 two chicken manures without or bearing roxarsone metabolites (CM and ROXCM),

220 respectively.

221 ns refers to not significant at 0.05 level. 
$224(\mathrm{P}<0.001)$, but not in husk and straw, as compared to the CM treatment (Fig. 2).

225 Moreover, total arsenic in brown rice, husk and straw significantly differed with soil 226 type $(\mathrm{P}<0.001)$.
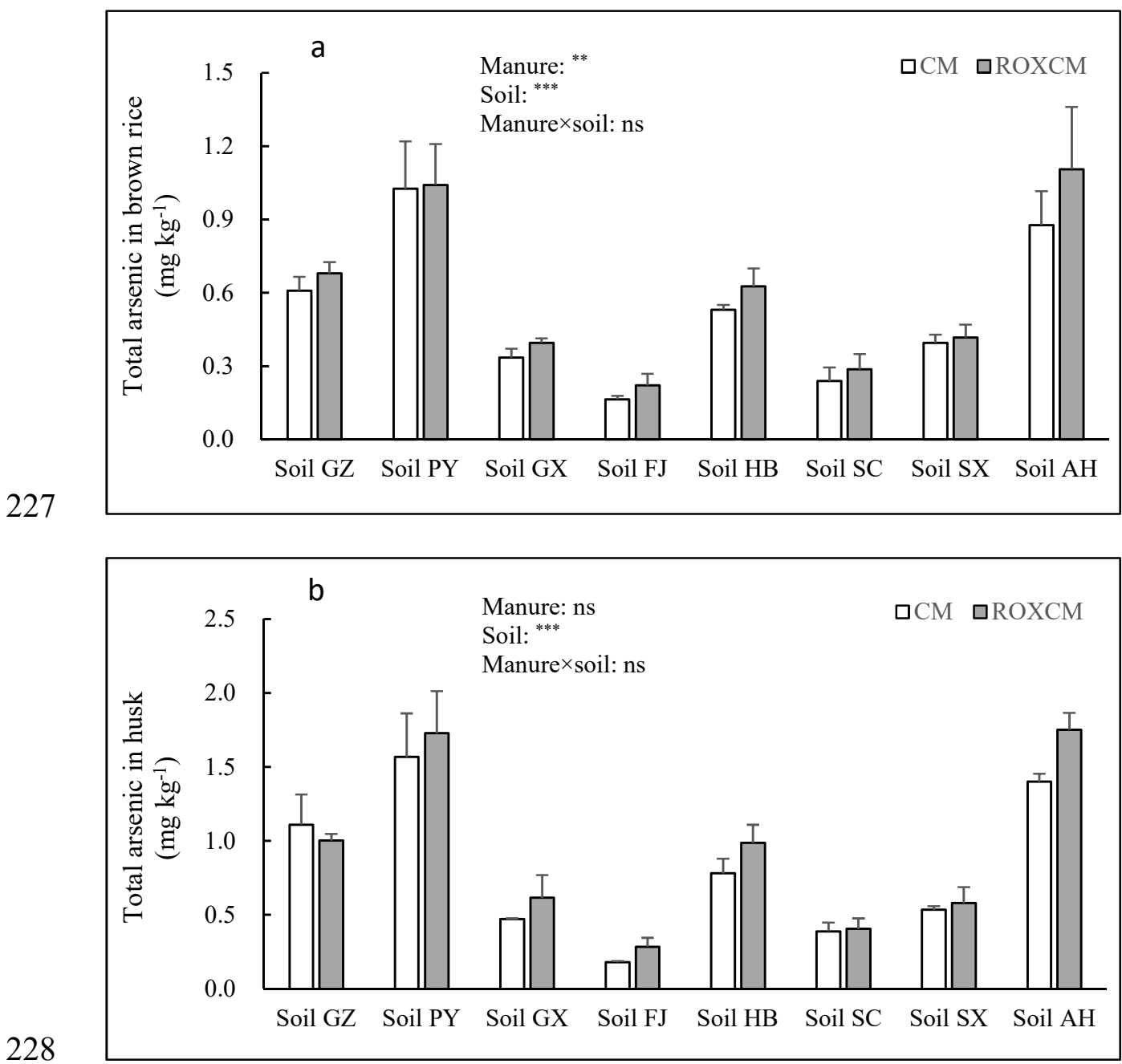


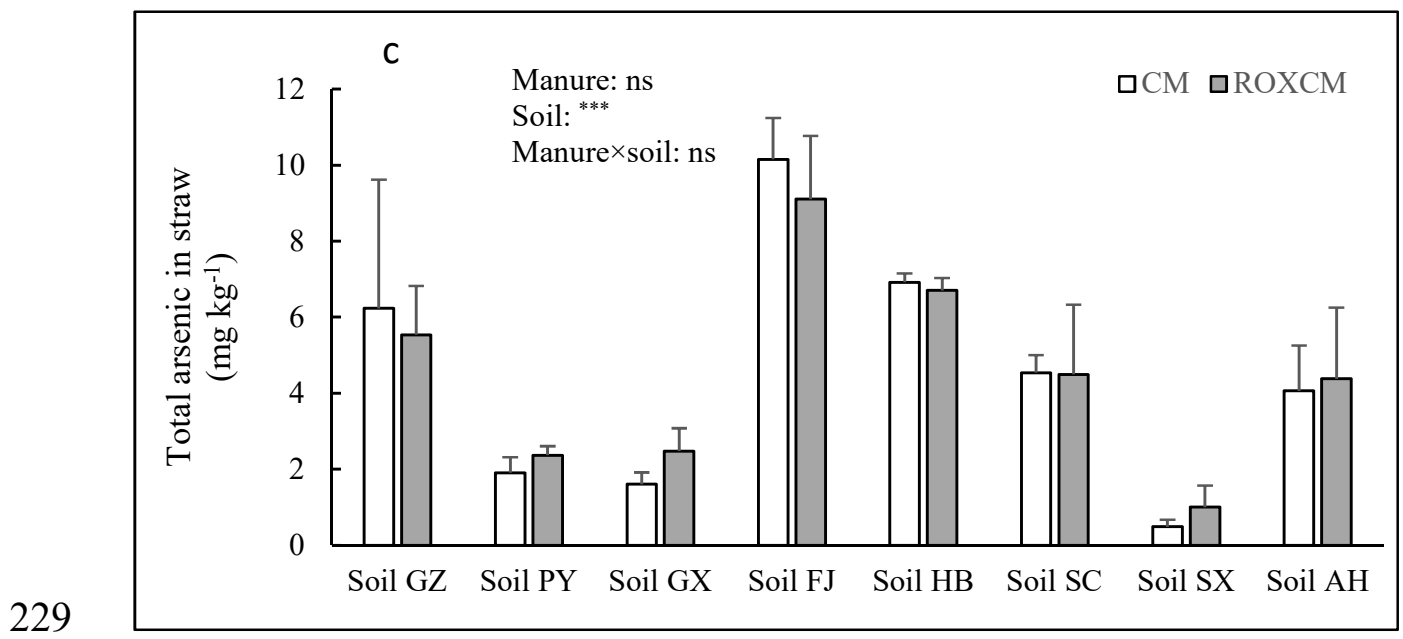

230 Fig. 2. Total arsenic in rice plants (a: brown rice; b: husk; c: straw) grown in eight

231 soils fertilized with two chicken manures without or bearing roxarsone metabolites

232 (CM and ROXCM), respectively.

233 ns refers to not significant at 0.05 level.

\section{$234 \quad 3.3$ Arsenic species in rice plant}

Although ROX, 3-AHPA, 3-AAHPA, As(III), As(V), MMA, DMA and some

236 unknown arsenic species were detectable in the ROXCM, only iAs, MMA and DMA

237 were determined in brown rice from all soils fertilized with ROXCM, the same as

238 those from soils amended with the control CM (Fig. 3a). Meanwhile, trace amounts of

239 Tetra were found in brown rice from the Soil PY-CM, Soil AH-CM and Soil AH-

240 ROXCM treatments as well. The occurrence of Tetra in rice grain was first identified

241 by Hansen et al. (2011), and was found in rice grain from Hunan province, China by

242 Jia et al. (2012). 
244 Soil AH-ROXCM treatment, while TMAO was detected in the husk from both

245 manure treatments in Soil GZ, Soil PY, Soil AH and the Soil HB-ROXCM treatment

246 (Fig. 3b).

247 All the five arsenic species were observed in the straw from all soils amended

248 with two manures, suggesting that the appearance of Tetra and TMAO in rice plants

249 were not associated with ROX metabolites in the manure (Fig. 3c). It has been

250 documented that TMAO in rice plant is taken up by rice root from soil solution and

251 cannot be converted by other arsenic species in rice plant (Arao et al., 2011; Jia et al.,

252 2012).

253 Though, being observed in the ROXCM, ROX was not detectable in all the rice

254 plants, which implies that rice could not take up ROX or ROX had completely

255 disappeared before rice root could absorb it. In our previous study, ROX and its

256 preliminary ROX metabolites such as 3-AHPA and 3-AAHPA completely degraded

257 while rice plant was harvested in soils applied with CM bearing ROX metabolites

258 (Yao et al., 2016). Since Tetra and TMAO in rice grain is not frequently found in

259 previous investigations, it is uncertain whether manure application is beneficial to

260 form these both arsenic compounds in flooded soil.

261 Additionally, DMA is the primary arsenic species in brown rice in this work since

262 methylated arsenic species such as DMA and MMA are easily translocated to the

263 above ground tissues (Zhao et al., 2010), which is different from the observation that 
arenite is the predominant species in brown rice grown in soils directly spiked with

265 external ROX (Liu et al., 2009). Hence, if ROX metabolites in the manure were

266 neglected, the potential direct human health risk caused by rice consumption

267 associated with ROX utilization in animal production would be exaggerated.
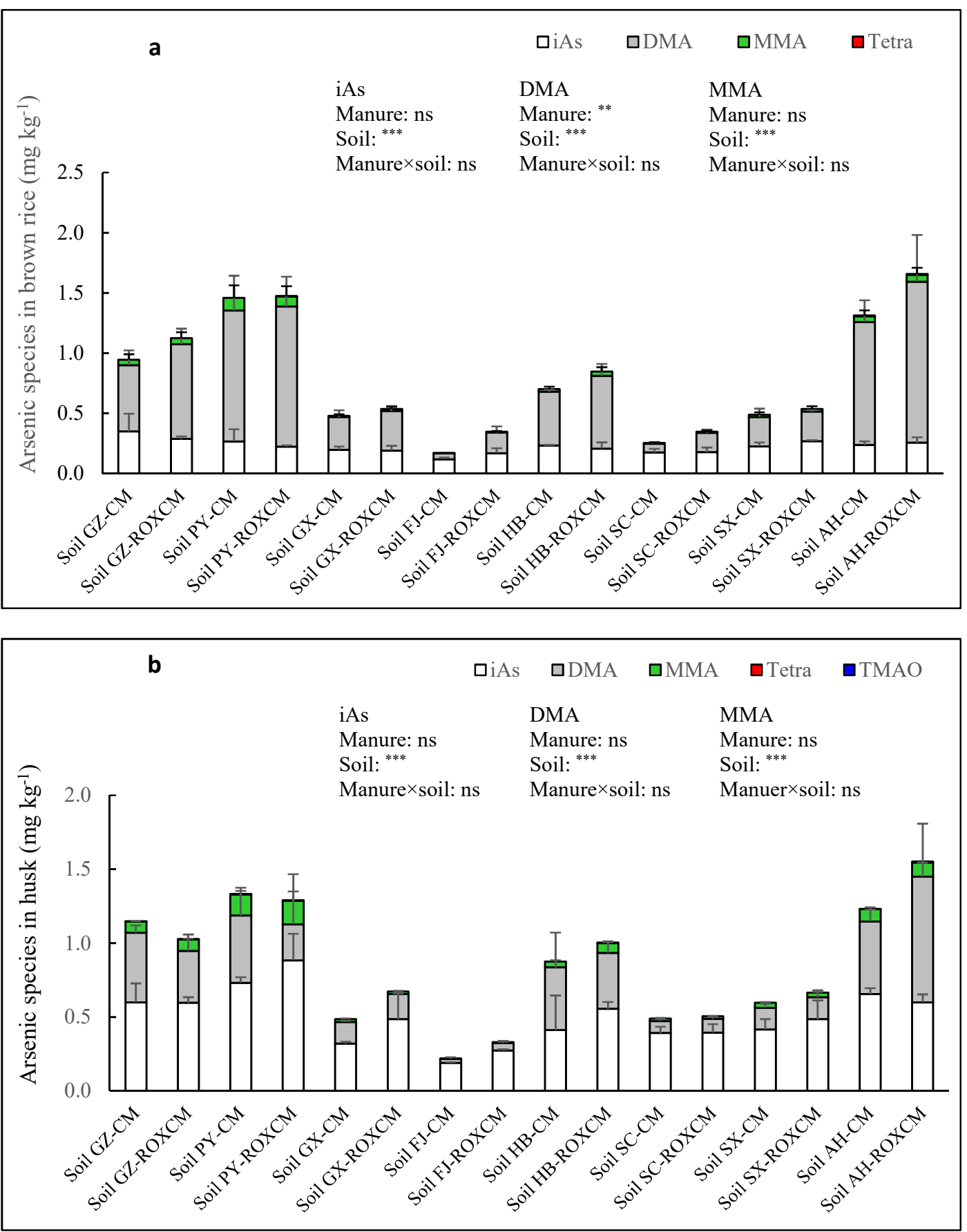


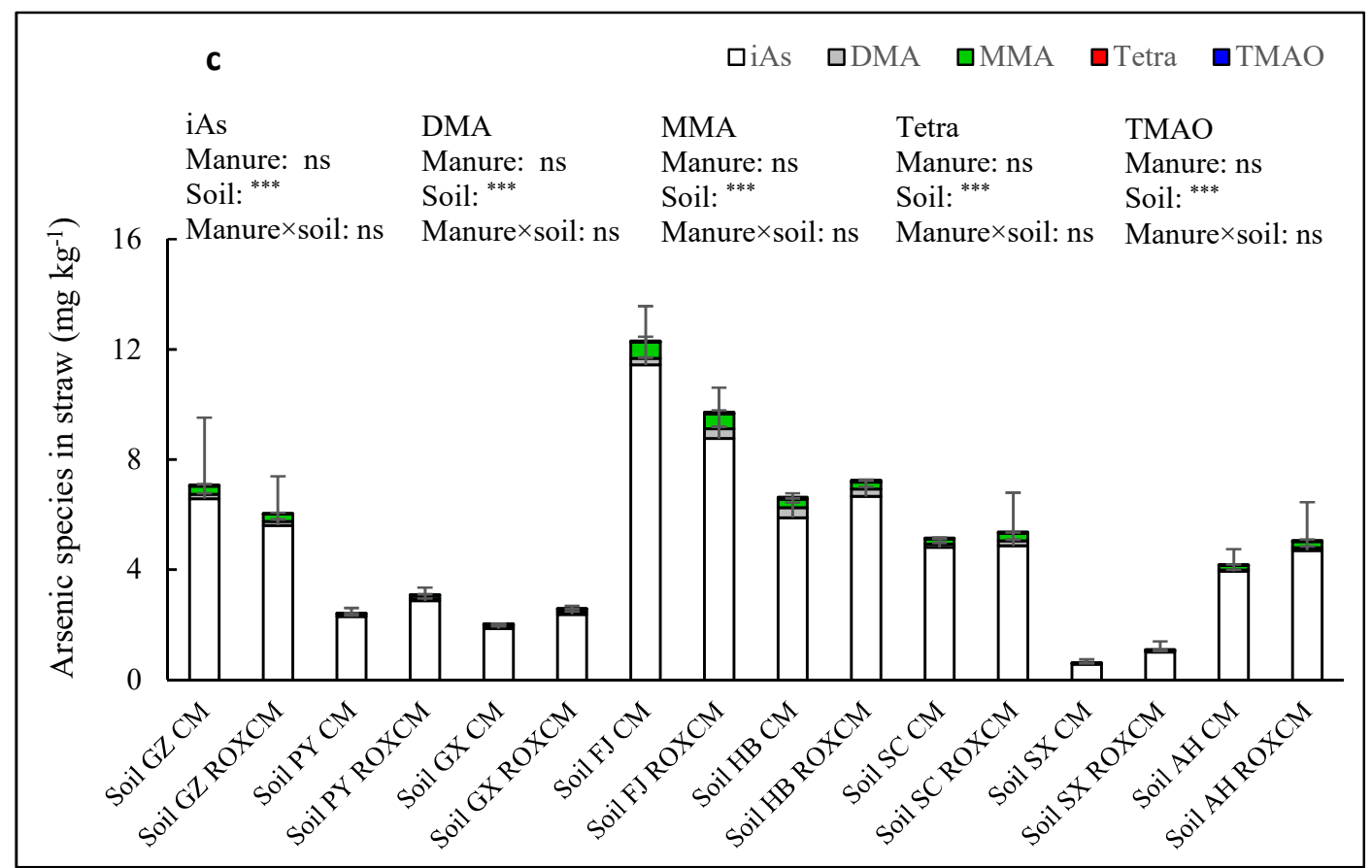

272 Fig. 3. Arsenic species in rice plants (a: brown rice; b: husk; c: straw) grown in eight

273 soils fertilized with two chicken manures without or bearing roxarsone metabolites

274 (CM and ROXCM), respectively.

275 ns refers to not significant at 0.05 level.

The concentrations of all arsenic species in rice plants were not influenced by

278 manure type, with the exception of significantly increased DMA in brown rice

279 fertilized with ROXCM as compared to that with $\mathrm{CM}(\mathrm{P}=0.002)$. The elevated brown

280 rice DMA can be explained by the dual effect of DMA supply in the ROXCM per se,

281 and the promotion of organic matter from the manure (Yao et al., 2016). It indicates

282 that though ROX and its metabolites occurred in the ROXCM, ROXCM application

283 solely and significantly increased DMA in brown rice, which contributes to the

284 significantly increased total arsenic in brown rice. However, soil type significantly 
285 affected the concentrations of all the detectable arsenic species in rice plants

$286 \quad(\mathrm{P}<0.001)$.

2873.5 Effect of soil properties on arsenic uptake by rice plant

Stepwise regression analysis shows that total arsenic in both brown rice and husk

289 from CM- or ROXCM-amended soils were solely dependent on soil free-iron oxides,

290 with the variance of soil free-iron oxides accounting for approximately $93.7 \%, 88.6 \%$,

$29192.5 \%$ and $89.4 \%$ of the difference of total arsenic in brown rice from both manure-

292 amended soils at the level of $<0.001$ (Table 4), respectively. However, straw total

293 arsenic from both manure-amended soils was primarily determined by soil $\mathrm{pH}$. The

294 variation of soil $\mathrm{pH}$ explained approximately $66.9 \%$ and $74.9 \%$ of the variability of

295 straw total arsenic at the level of $\leq 0.007$, respectively.

296 Although brown rice iAs in CM-amended soil was jointly influenced by soil $\mathrm{pH}$,

297 soil total arsenic and total $\mathrm{Mn}$, soil $\mathrm{pH}$ dominated the discrepancy of iAs among soils

298 with the variance accounting for $89.7 \%$ of the variability of iAs, and soil total arsenic

299 and total Mn had minor effect. In ROXCM-amended soil, brown rice iAs was solely

300 associated with soil $\mathrm{pH}$. Brown rice DMA and MMA were dependent on soil free-iron

301 oxides. The variation of soil free-iron oxides contributed to $83.6 \sim 94.9 \%$ of the total

302 variance of brown rice DMA and MMA in both manure-amended soils at the level of

$303<0.001$, with the exception that soil $\mathrm{pH}$ explained $4.8 \%$ of the total variance of brown

304 rice MMA in CM-amended soil. Though soil silt, soil total Mn or total Fe might be 
306 both manure-applied soils were primarily dependent on soil free-iron oxides. For the

307 five detectable arsenic species in straw from both manure-applied soils (with the

308 exception of straw MMA in CM-amended soil), soil $\mathrm{pH}$ was the only significant

309 variable determining arsenic accumulation in the straw $(\mathrm{P} \leq 0.016)$, with the variance

310 of soil $\mathrm{pH}$ accounting for $64.2 \sim 89.0 \%$ of the total variability of arsenic species.

311 Totally, there was no significant difference for arsenic uptake by rice plants

312 between CM and ROXCM, with the exception of significant enhanced brown rice

313 DMA in the ROXCM treatment. This indicates that whether ROX metabolites were

314 present in the $\mathrm{CM}$, or not, they did not alter the role of soil property on arsenic uptake

315 by rice plant. Moreover, soil factors governing the accumulation of total arsenic or

316 arsenic species in rice plant varied with plant tissue and arsenic species. The

317 assimilation of arsenic species in rice plants was enhanced predominantly by soil iron

318 oxides and $\mathrm{pH}$ in the present study, which is explained by the following mechanisms.

319 Firstly, iron oxides are the predominant arsenic adsorbents in hydromorphic

320 soils/paddy soils (Vithanage et al., 2013; Zhu et al., 2019). The two manures used

321 were abundant in organic matter, generating dissolved organic carbon into the soils,

322 which desorbs more arsenic in soils rich in indigenous iron oxides binding arsenic and

323 increases mobile arsenic in soil solutions for plant uptake (Syu et al., 2019; Williams

324 et al., 2011). Also, soils with high $\mathrm{pH}$ are commonly low in arsenic retention 
325 capability (Syu et al., 2019; Wang et al., 2015), which facilitates arsenic assimilation 326 in rice plants. 
roxarsone metabolites $(\mathrm{CM}$ and $\mathrm{ROXCM})$, respectively.

\begin{tabular}{|c|c|c|c|c|}
\hline Y & Model & $P$ value of variable & $\begin{array}{l}\text { Partial } \mathrm{R}^{2} \text { of } \\
\text { variable }\end{array}$ & $\begin{array}{l}\mathrm{P} \text { value } \\
\text { of model }\end{array}$ \\
\hline Brown rice total arsenic in $\mathrm{CM}$-amended soil & $\mathrm{Y}=0.0392$ Soil free-iron oxides & Soil free-iron oxide: $<0.001$ & 0.937 & $<0.001$ \\
\hline $\begin{array}{l}\text { Brown rice total arsenic in ROXCM-amended } \\
\text { soil }\end{array}$ & $\mathrm{Y}=0.4312$ Soil free-iron oxides & Soil free-iron oxides: $<0.001$ & 0.886 & $<0.001$ \\
\hline Husk total arsenic in CM-amended soil & $Y=0.0609$ Soil free-iron oxides & Soil free-iron oxides: $<0.001$ & 0.925 & $<0.001$ \\
\hline Husk total arsenic in ROXCM-amended soil & $\mathrm{Y}=0.0681$ Soil free-iron oxides & Soil free-iron oxides: $<0.001$ & 0.894 & $<0.001$ \\
\hline Straw total arsenic in $\mathrm{CM}$-amended soil & $\mathrm{Y}=0.6755$ Soil $\mathrm{pH}$ & Soil pH: 0.007 & 0.669 & 0.007 \\
\hline Straw total arsenic in ROXCM-amended soil & $\mathrm{Y}=0.6791$ Soil $\mathrm{pH}$ & Soil pH: 0.003 & 0.749 & 0.003 \\
\hline \multirow[t]{3}{*}{ Brown rice iAs in CM-amended soil } & $\begin{array}{l}\mathrm{Y}=0.0322 \text { Soil } \mathrm{pH}+0.0010 \text { Soil total } \\
\text { arsenic }-0.0002 \text { Soil total } \mathrm{Mn}\end{array}$ & Soil pH: 0.001 & 0.897 & $<0.001$ \\
\hline & & Soil total arsenic: 0.004 & 0.064 & \\
\hline & & Soil total Mn: 0.047 & 0.022 & \\
\hline Brown rice iAs in $\mathrm{ROXCM}$-amended soil & $\mathrm{Y}=0.0338$ Soil $\mathrm{pH}$ & Soil pH: $<0.001$ & 0.941 & $<0.001$ \\
\hline Brown rice DMA in CM-amended soil & $Y=0.0380$ Soil free-iron oxides & Soil free-iron oxides: $<0.001$ & 0.876 & $<0.001$ \\
\hline Brown rice DMA in ROXCM-amended soil & $\mathrm{Y}=0.0458$ Soil free-iron oxides & Soil free-iron oxides: $<0.001$ & 0.836 & $<0.001$ \\
\hline \multirow[t]{2}{*}{ Brown rice MMA in CM-amended soil } & $\begin{array}{l}Y=-0.0026 \text { Soil } \mathrm{pH}+0.0039 \text { Soil free- } \\
\text { iron oxides }\end{array}$ & Soil pH: 0.018 & 0.048 & $<0.001$ \\
\hline & & Soil free-iron oxides: $<0.001$ & 0.924 & \\
\hline
\end{tabular}


Brown rice MMA in ROXCM-amended soil Husk iAs CM-amended soil

Husk iAs ROXCM-amended soil Husk DMA in CM-amended soil Husk DMA in ROXCM-amended soil

Husk MMA in CM-amended soil Husk MMA in ROXCM-amended soil Straw iAs in CM-amended soil Straw iAs in ROXCM-amended soil Straw DMA in CM-amended soil Straw DMA in ROXCM-amended soil Straw MMA in CM-amended soil Straw MMA in ROXCM-amended soil Straw Tetra in CM-amended soil Straw Tetra in ROXCM-amended soil Straw TMAO in CM-amended soil Straw TMAO in ROXCM-amended soil
$\mathrm{Y}=0.0029$ Soil free-iron oxides

$\mathrm{Y}=0.0008$ Soil silt +0.0244 Soil freeiron oxides - 0.001 Soil Mg - 0.0012 Soil Olsen-P

$\mathrm{Y}=0.0169$ Soil total $\mathrm{Fe}$

$\mathrm{Y}=0.0209$ Soil free-iron oxides

$\mathrm{Y}=0.0013$ Soil silt -0.0075 Soil total Mn

$\mathrm{Y}=0.0045$ Soil free-iron oxides

$\mathrm{Y}=0.0051$ Soil free-iron oxides

$\mathrm{Y}=0.6938$ Soil $\mathrm{pH}$

$\mathrm{Y}=0.6930$ Soil $\mathrm{pH}$

$\mathrm{Y}=0.0215$ Soil $\mathrm{pH}$

$\mathrm{Y}=0.0233$ Soil $\mathrm{pH}$

$\mathrm{Y}=0.0006$ Soil sand

$\mathrm{Y}=0.0343$ Soil $\mathrm{pH}$

$\mathrm{Y}=0.0012$ Soil $\mathrm{pH}$

$\mathrm{Y}=0.0012$ Soil $\mathrm{pH}$

$\mathrm{Y}=0.0044$ Soil $\mathrm{pH}$

$\mathrm{Y}=0.0047$ Soil $\mathrm{pH}$
Soil free-iron oxides: $<0.001$

0.949

Soil silt: $<0.001$

0.070

$<0.001$

$<0.001$

Soil free-iron oxides: $<0.001$

0.901

0.023

Soil Mg: 0.002

$<0.001$

Soil Olsen-P: 0.035

0.005

Soil total Fe: $<0.001$

0.926

Soil free-iron oxides: $<0.001 \quad 0.854$

0.710

0.221

Soil total Mn: 0.005

0.951

Soil free-iron oxides: $<0.001$

0.952

Soil free-iron oxides: $<0.00$

Soil pH: 0.009

0.642

Soil pH: 0.002

0.770

0.642

0.690

0.585

0.670

0.684

0.748

0.822

0.890
$<0.001$

$<0.001$

$<0.001$

$<0.001$

$<0.001$

0.009

0.002

0.009

0.005

0.016

0.007

0.006

0.003

$<0.001$

$<0.001$ 
332 application might not pose serious arsenic health impact to human due to its low 333 toxicity to organisms (Zhao et al., 2010), however, it might lead to "straighthead" 334 symptom, a physical disorder linked with arsenic (DMA in particular) in rice plant 335 (Agrama and Yan, 2009; Limmer et al., 2018; Rahman et al., 2008; Yan et al., 2005). 336 "Straighthead" is characterized by sterile florets, poorly developed panicles and yield 337 loss, and reported in the U.S.A, Thailand, Japan, Australia, Argentina and elsewhere 338 (Belefant-Miller and Beaty, 2007; Dunn et al., 2006; Takeoka et al., 1990; Weerapat, 339 1979; Yan et al., 2010). Incorporation of monosodium methylarsenate (Belefant340 Miller, 2012; Yan et al., 2008), organic matter such as barley straw and stubble 341 residues of rice or winter cereal (Williams, 2005) and external DMA (Limmer et al., 342 2018) easily induces or intensifies straighthead.

343 Though the biomass of rice plants, grain yield in particular in all soils were not

344 inhibited by ROX metabolites in the present investigation, we are not sure whether

345 ROXCM application facilitates the growth environment suitable for straighthead

346 occurrence because cultivar difference of resistance to straighthead is indeed found in 347 rice (Li et al., 2017; Yan et al., 2005) and the susceptibility of the used cultivar 348 "Meixiangzhan" to straighthead was not be examined. It is noticeable that only 349 nineteen cultivars, 18 indica and 1 japonica, among a total of 124 Chinese cultivars 350 including 109 indica and 15 japonica, have been identified as straighthead resistant 351 (Yan et al., 2005). Natural occurred straighthead disorder has not yet be documented 
352 in China, but the possibility of straighthead disorder caused by application of animal

353 manure containing ROX metabolites is worthy to be further investigated because crop

354 losses range from $10 \%$ to $30 \%$ in medium grains and up to $90 \%$ in short and long

355 grains in other countries (Takeoka et al., 1990; Williams, 2005).

\section{4. Conclusion}

The growth of rice plant was not influenced by ROX metabolites in the manure,

358 but significantly varied with soil type. Arsenic species detectable in rice plant were

359 unrelated to ROX metabolites. ROX metabolites did not increase total arsenic or

360 arsenic species in straw and husk, except that total arsenic in brown rice was

361 significantly enhanced by ROX metabolites, most of which generated from

362 significantly increased DMA. The accumulation of total arsenic and arsenic species in

363 rice plant was governed by soil free-iron oxides or $\mathrm{pH}$. The results indicate that

364 animal manure bearing ROX metabolites should not be applied in soils rich in free-

365 iron and/or with high $\mathrm{pH}$ to minimum the occurrence of straighthead disorder in rice.

367 Acknowledgements

368 This work was financed by the China Scholarship Council (201708440109) and

369 the National Natural Science Foundation of China (Grants No. 41071316 and

370 40871226). 


\section{Declarations of interest}

$$
\text { None. }
$$

\section{References}

Agrama, H. A., Yan, W. G., 2009. Association mapping of straighthead disorder induced by arsenic in Oryza sativa. Plant Breeding. 128, 551-558.

Arao, T., Kawasaki, A., Baba, K., Matsumoto, S., 2011. Effects of arsenic compound amendment on arsenic speciation in rice grain. Environ Sci Technol. 45, 12911297.

Belefant-Miller, H., 2012. Specific panicle responses resulting from MSMA-induced straighthead sterility in rice. Plant Growth Regul. 66, 255-264.

Belefant-Miller, H., Beaty, T., 2007. Distribution of arsenic and other minerals in rice plants affected by natural straighthead. Agron J. 99, 1675.

Carrijo, D. R., Li, C., Parikh, S. J., Linquist, B. A., 2019. Irrigation management for arsenic mitigation in rice grain: Timing and severity of a single soil drying. Sci Total Environ. 649, 300-307.

Datta, R., Sarkar, D., Sharma, S., Sand, K., 2006. Arsenic biogeochemistry and human health risk assessment in organo-arsenical pesticide-applied acidic and alkaline soils: An incubation study. Sci Total Environ. 372, 39-48.

Dunn, B. W., Batten, G. D., Dunn, T. S., Subasinghe, R., L.Williams, R., 2006. Nitrogen fertiliser alleviates the disorder straighthead in Australian rice. Austr J Exp Agric Ecosyst Environ. 46, 1077-1083. 
393

394

395

Fisher, D. J., Yonkos, L. T., Staver, K. W., 2015. Environmental concerns of roxarsone in broiler poultry feed and litter in Maryland, USA. Environ Sci Technol. 49, 1999-2012.

Fu, Y., Chen, M., Bi, X., He, Y., Ren, L., Xiang, W., Qiao, S., Yan, S., Li, Z., Ma, Z., 2011. Occurrence of arsenic in brown rice and its relationship to soil properties from Hainan Island, China. Environ Pollut. 159, 1757-1762.

Hansen, H. R., Raab, A., Price, A. H., Duan, G., Zhu, Y., Norton, G. J., Feldmann, J., Meharg, A. A., 2011. Identification of tetramethylarsonium in rice grains with elevated arsenic content. J Environ Monit. 13, 32-34.

Huang, L., Yao, L., He, Z., Zhou, C., Li, G., Yang, B., Deng, X., 2014. Roxarsone and its metabolites in chicken manure significantly enhance the uptake of As species by vegetables. Chemosphere. 100, 57-62.

Jia, Y., Huang, H., Sun, G. X., Zhao, F. J., Zhu, Y. G., 2012. Pathways and relative contributions to arsenic volatilization from rice plants and paddy soil. Environ Sci Technol. 46, 8090-8096.

Li, G., Sun, G. X., Williams, P. N., Nunes, L., Zhu, Y. G., 2011. Inorganic arsenic in Chinese food and its cancer risk. Environ Int. 37, 1219-1225.

Li, X., Hu, B., Pan, X., Zhang, N., Wu, D., 2017. Association analysis of arsenicinduced straighthead in rice (Oryza sativa L.) based on the selected population with a modified model. Biomed Res Int. 2017, 1-6.

Limmer, M. A., Wise, P., Dykes, G. E., Seyfferth, A. L., 2018. Silicon decreases 

disorder. Environ Sci Technol. 52, 4809-4816.

Liu, C. W., Lin, C. C., Cheng, C. S., Sheu, G. R., Tsui, L., 2009. Arsenic accumulation by rice grown in soil treated with roxarsone. J Plant Nutr Soil Sci. 172, 550556.

Lu, R. K., 2000. Method of soil and agrochemical analysis (in Chinese). China Agricultural Science \& Technology Press, Beijing.

Meharg, A. A., Williams, P. N., Adomako, E., Lawgali, Y. Y., Deacon, C., Villada, A., Islam, R., Hossain, S., Yanai, J., 2009. Geographical variation in total and inorganic arsenic content of polished (white) rice. Environ Sci Technol. 43, $1612-1617$.

Mondal, D., Polya, D. A., 2008. Rice is a major exposure route for arsenic in Chakdaha block, Nadia district, West Bengal, India: A probabilistic risk assessment. Appl Geochem. 23, 2987-2998.

Rahman, M. A., Hasegawa, H., Rahman, M. M., Miah, M. A. M., Tasmin, A., 2008. Straighthead disease of rice (Oryza sativa L.) induced by arsenic toxicity. Environ Exp Bot. 62, 54-59.

432 Signes-Pastor, A. J., Carey, M., Meharg, A. A., 2017. Inorganic arsenic removal in rice bran by percolating cooking water. Food Chem. 234, 76-80.

434 Su, Y. H., McGrath, S. P., Zhao, F. J., 2010. Rice is more efficient in arsenite uptake 
and translocation than wheat and barley. Plant Soil. 328, 27-34.

Syu, C.-H., Wu, P.-R., Lee, C.-H., Juang, K.-W., Lee, D.-Y., 2019. Arsenic phytotoxicity and accumulation in rice seedlings grown in arseniccontaminated soils as influenced by the characteristics of organic matter amendments and soils. J Plant Nutr Soil Sci. 182, 60-71.

Takeoka, Y., Tsutsui, Y., Matsuo, K., 1990. Morphogenetic alterations of spikelets on a straighthead panicle in rice. Jpn J Crop Sci. 59, 785-791.

Vithanage, M., Rajapaksha, A. U., Wijesekara, H., Weerarathne, N., Ok, Y. S., 2013. Effects of soil type and fertilizer on As speciation in rice paddy contaminated with As-containing pesticide. Environ Earth Sci. 71, 837-847.

Wang, F. M., Chen, Z. L., Zhang, L., Gao, Y. L., Sun, Y. X., 2006. Arsenic uptake and Accumulation in Rice (Oryza sativa L.) at different growth stages following soil incorporation of roxarsone and arsanilic Acid. Plant Soil. 285, 359-367.

Wang, Y., Sun, L., Han, T., Si, Y., Wang, R., 2015. Arsenite and arsenate leaching and retention on iron (hydr)oxide-coated sand column. J Soils Sed. 16, 486-496.

Weerapat, P., 1979. Straighthead disease of rice suspected in southern Thailand. IRRN. 4, 67.

Williams, P., Investigating links between minerals in rice grain and straighthead. Cooperative Research Centre for Sustainable Rice Production, 2005, pp. 1-30. Williams, P. N., Villada, A., Deacon, C., Raab, A., Figuerola, J., Green, A. J., Feldmann, J., Meharg, A. A., 2007. Greatly enhanced arsenic shoot 
assimilation in rice leads to elevated grain levels compared to wheat and barley. Environ Sci Technol. 41, 6854-6859.

Williams, P. N., Zhang, H., Davison, W., Meharg, A. A., Hossain, M., Norton, G. J., Brammer, H., Islam, M. R., 2011. Organic matter-solid phase interactions are critical for predicting arsenic release and plant uptake in Bangladesh paddy soils. Environ Sci Technol. 45, 6080-6087.

Yan, W., Agrama, H. A., Slaton, N. A., Gibbons, J. W., 2008. Soil and plant minerals associated with rice straighthead disorder induced by arsenic. Agron J. 100,

Yan, W., Dilday, R. H., Tai, T. H., Gibbons, J. W., McNew, R. W., Rutger, J. N., 2005. Differential response of rice germplasm to straighthead induced by arsenic. Crop Sci. 45, 1223.

Yan, W. G., Correa, F., Marin, A., Marassi, J., Li, X., Re, J., Comparative study on induced straighthead in the U.S. with natural straighthead in the U.S. with natural straighthead in Argentina. Proceedings of the 33rd Rice Technical Working Group conference, Biloxi, Mississippi, Miss, USA, 2010. chickens. Environ Sci Technol. 50, 6737-6743.

476 Yao, L. X., Huang, L. X., Bai, C. H., He, Z. H., Zhou, C. M., 2017. Soil calcium 

roxarsone and its metabolites. Environ Sci Pollut Res. 24, 16429-16439. Delivery of roxarsone via chicken diet $\rightarrow$ chicken $\rightarrow$ chicken manure $\rightarrow$ soil $\rightarrow$ rice plant. Sci Total Environ. 566-567, 1152-1158. speciation in turnip as affected by application of chicken manure bearing roxarsone and its metabolites. Plant Soil 316, 117-124.

Zhao, F. J., McGrath, S. P., Meharg, A. A., 2010. Arsenic as a food chain contaminant: Mechanisms of plant uptake and metabolism and mitigation strategies. Annu. Rev. Plant Biol. 61, 535-559. in paddy field amendment with bismuth impregnated biochar. Sci Total rice: a global health issue? Environ Pollut. 154, 169-171. 